\title{
Time Series Analysis of Soil Freeze and Thaw Processes in Indiana
}

\author{
Tushar Sinha And Keith A. Cherkauer \\ Department of Agricultural and Biological Engineering, Purdue University, West Lafayette, Indiana
}

(Manuscript received 24 May 2007, in final form 18 February 2008)

\begin{abstract}
Seasonal cycles of freezing and thawing influence surface energy and water cycle fluxes. Specifically, soil frost can lead to the reduction in infiltration and an increase in runoff response, resulting in a greater potential for soil erosion. An increase in the number of soil freeze-thaw cycles may reduce soil compaction, which could affect various hydrologic processes. In this study, the authors test for the presence of significant trends in soil freeze-thaw cycles and soil temperatures at several depths and compare these with other climatic variables including air temperature, snowfall, snow cover, and precipitation. Data for the study were obtained for three research stations located in northern, central, and southern Indiana that have collected soil temperature observations since 1966. After screening for significant autocorrelations, testing for trends is conducted at a significance level of 5\% using Mann-Kendall's test. Observations from 1967 to 2006 indicate that air temperatures during the cold season are increasing at all three locations, but there is no significant change in seasonal and annual average precipitation. At the central and southern Indiana sites, soil temperatures are generally warming under a bare soil surface, with significant reductions in the number of days with soil frost and freeze-thaw cycles for some depths. Meanwhile, 5-cm soils at the northernmost site are experiencing significant decreases in cold season temperatures, as an observed decrease in annual snowfall at the site is counteracting the increase in air temperature. Seasonal mean maximum soil temperatures under grass cover are increasing at the southernmost site; however, at the central site, it appears that seasonal minimum soil temperatures are decreasing and the number of freezethaw cycles is increasing.
\end{abstract}

\section{Introduction}

Soil frost influences the physical properties of soil, primarily through the presence of ice. Ice in soil reduces water movement, leading to higher moisture retention (Benoit and Bornstein 1970). It also impedes infiltration and increases runoff response during snowmelt events (Kane and Chacho 1990). Studies indicate that seasonal infiltration is inversely related to the total moisture content of a frozen soil at the time of melt (Zhao et al. 1997; Zhao and Gray 1999). Infiltration into a frozen soil surface is affected by changes in soil structure, pore-size distribution, and hydraulic conductivity related to the formation of soil ice (Hillel 1998). A field study at a compacted clay site in southeastern Michigan observed an increase in near-surface hydraulic conductivity by factors of 50-300 for soils that experienced freezing and thawing cycles (Benson et al.

Corresponding author address: Tushar Sinha, Agricultural and Biological Engineering Department, 225 S. University St., West Lafayette, IN 47907.

E-mail: sinhat@purdue.edu
1995). Freezing and thawing cycles also increase soil erosion potential through the weakening of soil bonds, especially when soils have recently thawed (Froese et al. 1999). During the freezing process, expansion of ice in the soil void space pushes soil particles apart, reducing particle cohesion and soil strength while increasing the potential for soil erosion (Gatto and Ferrick 2003; Ferrick and Gatto 2004). Additionally, soil frost plays a role in the formation and stability of soil aggregates. Bryan (1971) found that an increase in initial soil moisture content decreases soil aggregation with rapid freezing rates while increasing aggregation for slow rates of freezing.

Seasonal soil frost and snow cover influence the regional surface energy and moisture balance by changing thermal and hydrological characteristics of the ground surface during melting (Zhang and Armstrong 2001; Groisman et al. 1994; Cherkauer and Lettenmaier 2003). The presence of a snowpack on the soil surface decreases soil frost penetration because snow acts as an insulating layer between the soil surface and colder air temperatures (Cherkauer and Lettenmaier 1999; Nyberg et al. 2001; Bayard et al. 2005). Zhang (2005) ob- 
served a significant decrease in the amplitude of diurnal changes in soil temperature at a depth of $5 \mathrm{~cm}$ when the ground surface was covered with snow. Thin snow cover retained by grass or vegetation on the ground surface can increase the insulation of the soil, which may reduce diurnal fluctuations in soil temperature, retarding the freezing and thawing processes (Shanley and Chalmers 1999). Additionally, snowmelt over soil frost in open areas can yield significant increases in spring streamflow as a result of the presence of ice, which reduces soil infiltration capacity (Dunne and Black 1971; Stadler et al. 1996). Several studies in the upper Mississippi River basin indicate an increased flooding in winter and spring during the late twentieth century as a result of earlier snowmelt by warmer air temperatures (Baldwin and Lall 1999; Knox 2001).

Soil temperature is a sensitive climate indicator because it integrates meteorological variables and all processes occurring at and above the ground surface including effects as a result of air temperature, snowfall, moisture contents, and freeze-thaw cycles (Zhang et al. 2001). Soil temperature influences physical, biological, and microbiological processes occurring in the soil. Changes in soil temperature are directly related to increases in both air temperature and precipitation during winter months (Zhang et al. 2003). An analysis of soil temperature variations from 1967 to 2002 indicates a warming trend in soil temperatures for winter and spring seasons in the northern and northwestern United States (Hu and Feng 2003). In the Great Lakes region, historical observations of air temperature indicate an increase in the number of frost-free days by up to two weeks, shorter winters, and warmer annual average air temperatures since the early 1900s (Kling et al. 2003). Furthermore, Kling et al. suggested that temperatures will warm by $3^{\circ}-7^{\circ} \mathrm{C}$ in winter and by $3^{\circ}-11^{\circ} \mathrm{C}$ in summer by the end of the twenty-first century based on recent climate simulations. In the Northern Hemisphere, there has been a significant reduction in mean snow cover area and an earlier occurrence of spring snowmelt from 1972 to 2000 (Lemke et al. 2007). Lemke et al. also indicated that the maximum area covered by seasonally frozen ground has decreased by about $7 \%$ in the Northern Hemisphere since the 1900s. Hardy et al. (2001) suggested that the shifting of regional climate toward less snowfall and shorter durations of snow on the ground will increase the depth and duration of soil freezing, leading to colder soil temperatures in temperate forests.

It is clear from these studies that there is a complex interaction between soil frost dynamics and other climate variables such as air temperature, snow, and precipitation. The objective of this study is to perform a hydrologic time series analysis to identify statistically significant trends in soil frost indicators such as the number of soil freeze-thaw cycles and mean soil temperatures during winter. An analysis of freeze-thaw cycles at various soil depths for three sites-in northern, central and southern Indiana-has been performed by Dale et al. (1981) from 1965 to 1980 . In this study, we extend the duration of the analysis and include additional variables to describe seasonal and annual variability in soil frost, identify their dynamic relationships based upon annual and seasonal statistics, and compare significant trends of soil frost variables with other meteorological variables.

\section{Methods}

Several studies have used different calculation methods to obtain freeze-thaw cycles (Baker and Ruschy 1995; Hershfield 1974; Schmidlin et al. 1987). In this study, the minimum threshold required for a soil to be frozen is over two consecutive days, both daily minimum and at least one daily maximum soil temperature observation must be equal to or below $0^{\circ} \mathrm{C}$. For a soil to be declared thawed, a frozen soil must experience two consecutive days of daily maximum and at least one daily minimum soil temperature above $0^{\circ} \mathrm{C}$. This buffers the analysis from the effects of uncertainty in the measurements. Fluctuations of soil state between frozen and thawed are defined as freeze-thaw cycles. Soil frost is defined as the state in which soil temperature is less than or equal to $0^{\circ} \mathrm{C}$ and soil moisture is frozen or has begun to freeze. Seasonal frost areas are regions in which soil temperature falls below $0^{\circ} \mathrm{C}$ during the winter season and thaws completely during the following summer (Departments of the Army and the Air Force 1987).

This study employs long-term observational records of soil temperature and surface meteorology to test for statistically significant trends in variables associated with the formation and hydrological significance of seasonal soil frost. Details concerning the source and location of observational records, quality control of data, and computation of soil frost development statistics and testing for statistically significant trends are described in this section.

\section{a. Observational data}

Soil temperature data from three Indiana research stations (Fig. 1) is chosen for this study based on the length of record and availability of soil temperature profile data and additional meteorological observations. Pinney-Purdue Agricultural Center (PPAC) near Wanatah, Indiana, is the northernmost site, with sen- 


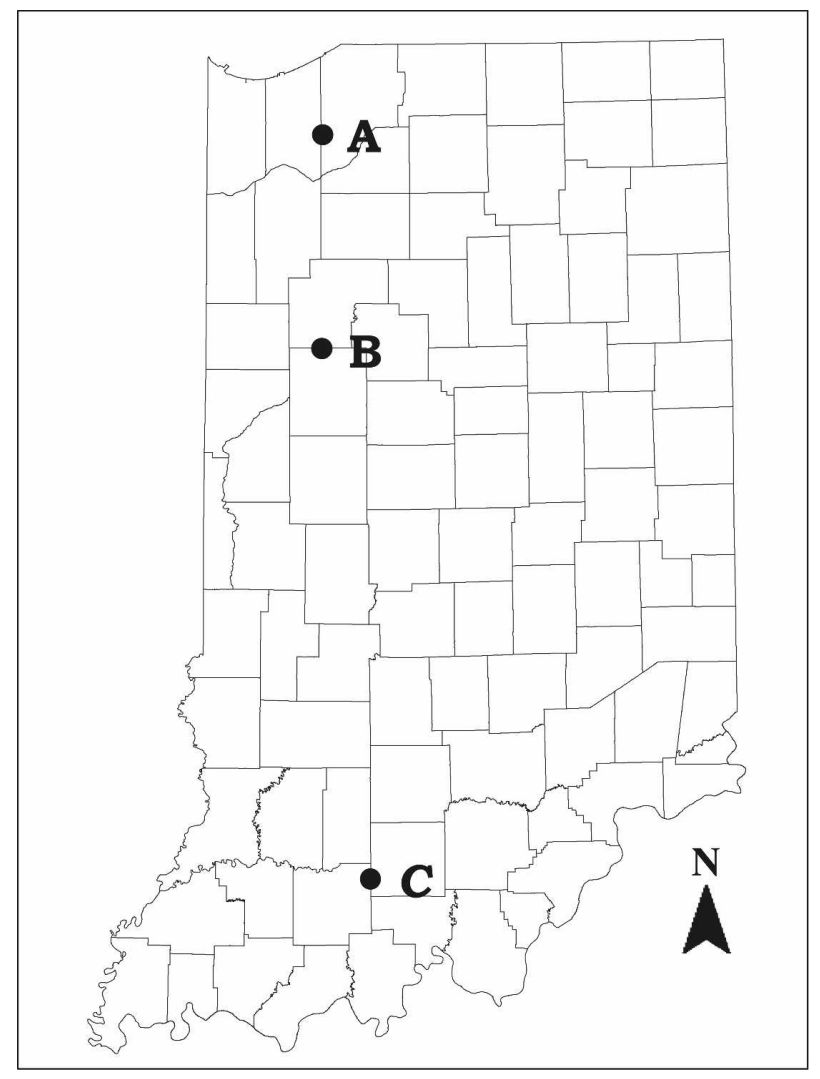

FIG. 1. Map showing location of three Indiana research stations that have been collecting soil temperatures and other meteorological data since 1966: (a) PPAC near Wanatah, (b) ACRE near West Lafayette, and (c) SIPAC near Dubois.

sors installed in Tracy (coarse-loamy, mixed, active, mesic Ultic Hapludalfs) sandy loam soil at an elevation of $224 \mathrm{~m}$. The central station, the Agronomy Center for Research and Education (ACRE) near West Lafayette, Indiana, sits on Russell (Fine-silty, mixed, superactive, mesic Typic Hapludalfs) and Raub (Fine-silty, mixed, superactive, mesic Aquic Argiudolls) silt loam soil at an elevation of $215 \mathrm{~m}$. The southernmost site is located at the Southern Indiana Purdue Agricultural Center (SIPAC) near Dubois, Indiana, which has Zanesville (Fine-silty, mixed, active, mesic Oxyaquic Fragiudalfs) silt loam soils and an elevation of $212 \mathrm{~m}$. The three sites are situated in regions of low topographic slope. Because sandy loam soils have lower water retention than silt loam soils, soil at the northern site is expected to have different thermal properties and frost dynamics than the soils at the other two sites.

Daily minimum and maximum soil temperatures, with some exceptions, have been collected for a soil depth of $10 \mathrm{~cm}$ under grass cover and at soil depths of 5,10 , and $20 \mathrm{~cm}$ below bare soil surface at all three locations since 1966. Soil temperature data from 1982 onwards are available from the National Climatic Data Center's (NCDC) Summary of the Day (SOD) surface dataset (available online at http://www.ncdc.noaa.gov/ oa/ncdc.html). Prior to 1982, soil temperature data are available only through paper records in the annual volumes of climatological data for Indiana (Department of Commerce 1966-1982). These records have been digitized as part of this analysis. Meteorological observations including precipitation, air temperature, and snow depth are also obtained from the NCDC's SOD surface datasets since 1966 for all three sites.

Exceptions to the above general description of the observational dataset are limited to PPAC. Soil temperature data at 5 and $10 \mathrm{~cm}$ below bare soil are only available starting in 1971 and 1969, respectively. For both the 5- and 10-cm depths at PPAC, data for 1982 are not used in the analysis as a result of a large number of missing observations of soil temperature. Observations for grass at $10 \mathrm{~cm}$ and bare soil at $20 \mathrm{~cm}$ for PPAC have not been included in the analysis because these data are not available for a minimum of 10 consecutive years, which is set as the threshold period for analysis.

\section{b. Data quality control}

Soil temperature data, obtained from both the electronic NCDC database and the digitized records, and other meteorological observations are passed through several quality control steps before they are tested for significant trends. These checks are designed to remove incorrect data as well as to check data for consistency and continuity.

Maximum and minimum air temperatures, total precipitation, snowfall, and snow depth data are subjected to quality control at NCDC using an automated program, Validation of Historical Daily Data (ValHiDD), developed by Reek et al. (1992). Additional processing is performed to identify gaps and missing dates in the records, which are then filled with a "no data value" to facilitate comparisons between variables for the full time series.

Soil and air temperature data from the NCDC database and digitized records are subjected to qualitycontrol procedures similar to the other meteorological variables but with the following rule modifications designed to reflect local conditions: the upper limit for both daily maximum soil and air temperatures is set to $47^{\circ} \mathrm{C}$, whereas the lower limit for daily minimum temperatures is set to $-38^{\circ} \mathrm{C}$ based on extreme values of air temperatures recorded in Indiana. The maximum daily air temperature of $47^{\circ} \mathrm{C}$ was observed at Collegeville in 1936 , and the minimum air temperature of $-38^{\circ} \mathrm{C}$ was observed at New Whiteland in 1994 (available online at http://www.agry.purdue.edu/climate/facts.asp). The 
maximum diurnal range of temperatures (maximum temperature minus minimum temperature on each day) is limited to $35^{\circ} \mathrm{C}$. Corrections are also made to the daily data to check for inconsistencies when minimum temperature on a given day exceeds the maximum temperature. On instances when daily maximum soil temperatures are below $0^{\circ} \mathrm{C}$, any missing daily minimum soil temperature is filled with a freezing temperature.

In some cases, both minimum and maximum soil temperatures are less than $0^{\circ} \mathrm{C}$ at 10 and $20 \mathrm{~cm}$ below bare soil, despite temperatures being above $1^{\circ} \mathrm{C}$ at $5-\mathrm{cm}$ depth on a day without any prior development of soil frost. In such suspicious cases, the data at deeper layers $(10$ and $20 \mathrm{~cm})$ are replaced with the "no data value." This check is designed to remove anomalously cold deep soil temperatures, which results in a loss of data ranging from $0.05 \%$ to $2 \%$ depending on the site. It is possible that this process has added a bias to the results because it ignores problems in deep soil layer observations during the cold season, but this effect is unlikely to be large because only a small number of measurements are affected.

Temperature spikes, defined as the absolute values resulting from taking differences on three consecutive days with a focus on the central value (Reek et al. 1992), are suggestive of errors in the temperature series. Spikes greater than $28^{\circ} \mathrm{C}$ are checked to remove unrealistic temperature differences (Feng et al. 2004; $\mathrm{Hu}$ and Feng 2003). Data identified as erroneous or suspicious are replaced with the "no data value."

Soil temperature measurements from the three stations are taken using a Palmer dial-type temperature sensor, which has a precision of $0.5^{\circ} \mathrm{C}$ (Schaal et al. 1981). This means that small variations in temperature, less than $0.5^{\circ} \mathrm{C}$, will not be observed. Diurnal variations in soil temperatures are small, especially when the soil is frozen, which is likely to produce the same reading for several consecutive days. To filter valid observations from failed sensors, the duration of constant temperature measurements are checked. Daily soil temperature data are treated as erroneous when the same value is measured at a depth for at least a month or longer (Hu et al. 2002). In all these erroneous cases, the first measurement is deemed to be valid, but all subsequent measurements are replaced with the "no data value."

\section{c. Data processing}

A time series analysis focuses on changes to annual and seasonal summary statistics with time. Annual summary statistics are based on water years starting 1 October and running through 20 September, where water year 1967 starts on 1 October 1966 and runs through
30 September 1967. The cold season statistics are computed for a period from October through April, which incorporates the earliest observed occurrence of soil frost and the latest observed thaw. The first day of soil frost is identified by selecting the first day after 1 October when the soil temperature meets the definition of being frozen. The last day of thawing is computed by identifying the last day of the water year when soil frost thaws.

The annual and seasonal variables are estimated from the daily time series and tested for the presence of significant trends.

i) Days when minimum air temperature $\left(T_{\text {air }}\right)$ is less than or equal to $0^{\circ} \mathrm{C}$ : computed by counting the number of days when $T_{\text {air }}$ is at or below $0^{\circ} \mathrm{C}$.

ii) Seasonal mean maximum $T_{\text {air }}$ : computed by estimating the mean of maximum daily $T_{\text {air }}$ during the cold season.

iii) Seasonal mean minimum $T_{\text {air }}$ : computed by estimating the mean of minimum daily $T_{\text {air }}$ during the cold season.

iv) Annual snowfall: computed by summing daily snowfall on an annual basis.

v) Snow cover index (SCI): the integration of snow cover thickness over time for the cold season (Zhang et al. 2001). It is estimated using

$$
\mathrm{SCI}=\int_{t_{1}}^{t_{2}} H_{s}(t) d t,
$$

where $t_{1}$ and $t_{2}$ are the first and the last day of snow on the ground, respectively, and $H_{s}$ is snow thickness greater than $2 \mathrm{~cm}$ at time $t$. The units of SCI are cm day.

vi) Annual and seasonal precipitation: computed by summing daily precipitation over a full water year and cold season, respectively.

vii) Annual freeze-thaw cycles: estimated by determining the number of times soil temperatures change between frozen and thawed states in a winter.

viii) Annual soil frost days: computed by counting the number of days when a soil is classified as frozen.

ix) Seasonal mean maximum $T_{\text {soil }}$ : computed at several depths by calculating the mean of maximum daily $T_{\text {soil }}$ during the cold season.

x) Seasonal mean minimum $T_{\text {soil }}$ : computed at several depths by calculating the mean of minimum daily $T_{\text {soil }}$ during the cold season.

xi) Seasonal extreme maximum $T_{\text {soil }}$ : computed by taking the maximum daily $T_{\text {soil }}$ during the cold season.

xii) Seasonal extreme minimum $T_{\text {soil }}$ : computed by taking the minimum daily $T_{\text {soil }}$ during the cold season. 


\section{d. Data analysis}

Data analysis is undertaken in three stages: (i) annual average values of soil frost variables and climatic conditions are compared to identify differences in soil frost development among the sites, (ii) annual and seasonal time series of observed and derived variables (section 2c) are studied to identify the dynamic relationships among them, and (iii) annual and seasonal time series data are analyzed to find statistically significant trends at various depths for all three sites. For the first stage, annual and cold seasonal variables are averaged for all years of observation and compared among the three sites. The Kruskal-Wallis test is used to identify statistically significant differences in the median values of the first day of soil frost and last day of thaw among the three sites. The median statistic is selected because it is resistant to outliers. For the second stage analysis, different variables for a single site and a single year or season are compared to explain anomalous soil frost development through changes in other observed variables. Finally, for the third stage, time series data are checked for significant autocorrelation and tested for trends using Mann-Kendall's test. The statistical tests used for the three analysis stages are discussed below.

\section{1) Kruskal-Wallis tests}

The Kruskal-Wallis test is a nonparametric version of the classical one-way analysis of variance (ANOVA), which is a statistical method used to check the relationships between one or more explanatory or predictor variables and a response variable. This test is close in power to an ANOVA when the data follow a normal distribution, but it may be more powerful when data are not normally distributed (Hirsch et al. 1992). It is used to compare sample medians from two or more groups and is applied in a form similar to that used by Hirsch et al. (1992). It assigns ranks to all the data, with rank 1 assigned to the lowest value and $\mathrm{N}$ to the highest. An average rank is used in the event of ties. For each of the $k$ groups of data, it computes the average rank $(\overline{\mathrm{Rj}})$ of the $n_{j}$ data values in the $j^{\text {th }}$ group. The test statistic KW is given by

$$
\mathrm{KW}=\frac{12}{N(N+1)} \sum_{j=1}^{k} n_{j}\left(\overline{\mathrm{Rj}}-\frac{N+1}{2}\right)^{2}
$$

The null hypothesis is that all samples are drawn from the same population (or drawn equivalently from different populations with the same distribution). This hypothesis is rejected if $\mathrm{KW} \geq \chi^{2}(1-\alpha, k-1)$, where $1-\alpha$ is the quartile of a chi-square distribution with $k-1$ degrees of freedom and a significance level of $\alpha$ (0.05 in this study).

\section{2) Autocorrelation tests}

In many cases, the presence of autocorrelation or serial correlation, defined as the correlation of a variable with itself over successive time intervals, increases the chances of detecting significant trends, even if they are absent and vice versa. Therefore, it is important to consider autocorrelation already present in the data series, prior to testing for trends. The effects of autocorrelation become insignificant after a lag of three in most seasonal and annual hydrologic series (Rao et al. 2003); thus, autocorrelations up to lag 3 are checked at a significance level of $5 \%$ on all time series to identify those that are significant.

\section{3) Time series trend anAlysis}

Time series trend analysis is performed on the annual and seasonal datasets described in section $2 \mathrm{c}$ at a significance level of $5 \%$ using a nonparametric MannKendall's test. Nonparametric methods often use the rank of the observations rather than the actual observations, which makes them less sensitive to the distribution of the data; thus they can be applied to nonnormally distributed data. Mann-Kendall's test has been widely used for trend analysis in hydrological studies (Lettenmaier et al. 1994; Lins and Slack 1999; Kunkel et al. 1999; Yue and Wang 2002; Birsan et al. 2005).

This nonparametric test is applied in a form similar to that used by Hirsch et al. (1992). Let $y_{t}$ be the annual time series with time $t=1, \ldots, N$. Each value $y_{t^{\prime}}$ at $t^{\prime}=1, \ldots, N-1$ is compared with all subsequent values $y_{t}$ at $t=t^{\prime}+1, t^{\prime}+2, \ldots, N$, and a new series $z_{k}\left(y_{t}-y_{t^{\prime}}\right)$ is generated by

$$
\begin{aligned}
& z_{k}=1 \quad \text { if } \quad y_{t}>y_{t^{\prime}}, \\
& z_{k}=0 \quad \text { if } \quad y_{t}=y_{t^{\prime}} \quad \text { and }, \\
& z_{k}=-1 \quad \text { if } \quad y_{t}<y_{t^{\prime}},
\end{aligned}
$$

where $k=\left(t^{\prime}-1\right)\left(2 N-t^{\prime}\right) / 2+\left(t-t^{\prime}\right)$. MannKendall's statistic is given by the sum of the $z_{k}$ series:

$$
S=\sum_{t^{\prime}=1}^{N-1} \sum_{t=t^{\prime}+1}^{N} z_{k}
$$

The test statistic represents the number of positive differences minus the number of negative differences for all the differences considered. Here, $S$ is asymptotically, normally distributed with mean of zero and variance given by

$$
\operatorname{Var}(S)=\frac{1}{18}\left[N(N-1)(2 N+5)-\sum_{i=1}^{n} e_{i}\left(e_{i}-1\right)\left(2 e_{i}+5\right)\right]
$$


TABLE 1a. Average annual and seasonal statistics for selected meteorological variables from 1967 to 2006.

\begin{tabular}{|c|c|c|c|c|c|c|}
\hline & \multicolumn{2}{|c|}{ PPAC } & \multicolumn{2}{|c|}{ ACRE } & \multicolumn{2}{|c|}{ SIPAC } \\
\hline & Average & Std dev & Average & Std dev & Average & Std dev \\
\hline Snow $(\mathrm{cm})^{*}$ & 106.8 & 40.6 & 54.4 & 28.2 & 22.5 & 22.2 \\
\hline $\mathrm{SCI}(\mathrm{cm} \text { day })^{*}$ & 698.0 & 575.5 & 323.1 & 340.6 & 77.9 & 89.3 \\
\hline Days minimum $T_{\text {air }} \leq 0^{\circ} \mathrm{C}$ & 138.3 & 18.0 & 130.8 & 10.6 & 107.1 & 13.4 \\
\hline Mean maximum $T_{\text {air }}\left({ }^{\circ} \mathrm{C}\right)^{* *}$ & 7.5 & 1.3 & 8.3 & 1.3 & 11.3 & 1.3 \\
\hline Mean minimum $T_{\text {air }}\left({ }^{\circ} \mathrm{C}\right)^{* *}$ & -2.8 & 1.2 & -2.0 & 1.3 & 0.1 & 1.1 \\
\hline Precipitation $(\mathrm{cm})$ & 94.4 & 14.5 & 95.1 & 11.9 & 119.8 & 20.0 \\
\hline
\end{tabular}

* SIPAC average statistics estimated from 1985 to 2006.

** Seasonal $T_{\text {air }}$.

where $n$ is the number of tied groups, and $e_{i}$ is the number of data values in the $i^{\text {th }}$ (tied) group. The standardized normal test statistic is given by

$$
Z=\left\{\begin{array}{ll}
\frac{S-1}{[\operatorname{Var}(S)]^{1 / 2}} ; & S>0 \\
0 ; \quad S=0 & \\
\frac{S+1}{[\operatorname{Var}(S)]^{1 / 2}} ; & S<0
\end{array} .\right.
$$

The trend is positive if $Z$ is positive and vice versa. This method relaxes the requirement of normally distributed data but still requires data to be random.

To consider the effect of autocorrelation, Hamed and Rao (1998) suggest a modified Mann-Kendall test, which calculates the autocorrelation between the ranks of the data after removing the apparent trend. The adjusted variance is given by

$$
\operatorname{Var}(S)=\frac{1}{18}[N(N-1)(2 N+5)] \frac{N}{N S^{*}},
$$

where

$$
\begin{aligned}
\frac{N}{N S^{*}}= & +\frac{2}{N(N-1)(N-2)} \sum_{i=1}^{p}(N-i)(N-i-1)(N \\
& -i-2) \rho_{s}(i) .
\end{aligned}
$$

Here, $N$ is the number of observations in the sample, $N S^{*}$ is the effective number of observations to account for autocorrelation in the data, $\rho_{s}(i)$ is the autocorrelation between ranks of the observations for lag $i$, and $p$ is the maximum time lag under consideration ( 3 for this study).

\section{Results and discussion}

\section{a. Average annual statistics for selected variables}

PPAC is the northernmost site of the study area (Fig. 1). Average annual observations from 1967 to 2006 in- dicate that it has the highest average values of snowfall and SCI, nearly twice that of ACRE, and more than 5 times that of the southernmost site, SIPAC (Table 1a). Similarly, the average annual number of days with minimum $T_{\text {air }} \leq 0^{\circ} \mathrm{C}$ is highest at PPAC with 138.3 days, but this is only 7 days longer than the average at ACRE. This difference between PPAC and ACRE is small, and it falls within a single standard deviation of annual observations for both stations. Both seasonal mean minimum $T_{\text {air }}$ and mean maximum $T_{\text {air }}$ for PPAC are $0.8^{\circ} \mathrm{C}$ colder than corresponding air temperatures at ACRE (Table 1a). SIPAC, however, experiences about 30 fewer days of freezing $T_{\text {air }}$ than PPAC, which indicates a distinctly warmer winter climate.

Precipitation among the stations varies inversely as compared to $T_{\text {air }}$, with SIPAC having the highest annual average values of $119.8 \mathrm{~cm}$. PPAC and ACRE have very similar average annual precipitations of 94.4 and $95.1 \mathrm{~cm}$, respectively. Although the annual precipitation and number of days with below freezing $T_{\text {air }}$ are similar between PPAC and ACRE, differences in the amount and timing of snowfall can result in distinct soil frost dynamics. At all three sites, annual standard deviations for both snowfall and SCI indicate higher yearto-year variability that may affect soil frost variables (Table 1a).

PPAC has the highest average number of annual freeze-thaw cycles, at a depth of $5 \mathrm{~cm}$ below the soil surface with 6.9 cycles; this is 1.4 times that of ACRE and is 2.8 times that of SIPAC (Table 1b). Similarly, the average annual number of soil frost days at PPAC is about 1.3 times that of ACRE and nearly 3 times that of SIPAC. This agrees with the observed differences in the number of days with minimum $T_{\text {air }} \leq 0^{\circ} \mathrm{C}$ among stations.

As expected, observations at the three sites indicate that the average number of freeze-thaw cycles and number of soil frost days are higher near the soil surface as compared to deeper soil layers (Table 1b). At PPAC, in contrast to the other two sites, there is a sharp 
TABLE 1b. Average annual statistics for selected soil frost variables from 1967 to 2006.

\begin{tabular}{|c|c|c|c|c|c|c|}
\hline & \multirow[b]{2}{*}{ Depth $(\mathrm{cm})$} & \multirow{2}{*}{$\begin{array}{c}\text { PPAC } \\
\text { Bare soil }\end{array}$} & \multicolumn{2}{|c|}{ ACRE } & \multicolumn{2}{|c|}{ SIPAC } \\
\hline & & & Grass $^{\mathrm{a}}$ & Bare soil & Grass $^{\mathrm{a}}$ & Bare soil \\
\hline \multirow[t]{3}{*}{ Soil freeze-thaw cycles } & $5^{\mathrm{b}}$ & 6.9 & - & 4.8 & - & 2.5 \\
\hline & $10^{\mathrm{c}}$ & 2.3 & 1.5 & 3.1 & 0.4 & 1.6 \\
\hline & 20 & - & - & 2.0 & - & 0.3 \\
\hline \multirow{3}{*}{ Soil frost days } & 5 & 57.6 & - & 45.4 & - & 19.0 \\
\hline & 10 & 31.6 & 22.1 & 43.5 & 5.0 & 17.4 \\
\hline & 20 & - & - & 32.6 & - & 3.9 \\
\hline \multirow[t]{3}{*}{ Soil frost days per freeze-thaw cycles } & 5 & 8.3 & - & 9.5 & - & 7.6 \\
\hline & 10 & 13.7 & 14.7 & 14.0 & 12.5 & 10.9 \\
\hline & 20 & - & - & 16.3 & - & 13.0 \\
\hline
\end{tabular}

${ }^{a}$ Grass estimated from 1967-2001.

${ }^{\mathrm{b}}$ Estimated from 1972-2006 at PPAC.

${ }^{\mathrm{c}}$ Estimated from 1970-2006 at PPAC.

decrease in the annual average number of freeze-thaw cycles and soil frost days as we move from 5 to $10 \mathrm{~cm}$ below the bare soil surface (Table $1 \mathrm{~b}$ ). This may be related to the differences in snow cover, which is substantially deeper and longer lasting at PPAC (Table 1a) and also a result of the differences in soil types between the sites (sandy loam at PPAC versus silt loams at ACRE and SIPAC).

As the depth from soil surface increases at a site, the ratio of soil frost days to freeze-thaw cycles also increases. This indicates that the deeper layers tend to stay frozen for more consecutive days upon freezing, despite being frozen less often than the layers closer to the surface. For instance, many early season freezethaw cycles are short in duration and are confined to the $5-\mathrm{cm}$ depth. This can result in lower ratios of soil frost days to freeze-thaw cycles for the shallower soils.

Soil freeze-thaw cycles and the number of soil frost days are fewest at a depth of $20 \mathrm{~cm}$ for both ACRE and SIPAC, reflecting the decreasing occurrence of soil frost with depth. For instance, the soils at the southern site, SIPAC, are frozen for only 3.9 days on average at a depth of $20 \mathrm{~cm}$. Besides the effect of soil depth, the presence of grass at the surface also reduces the number of freeze-thaw cycles and the number of soil frost days. At ACRE, the grass-covered site experiences

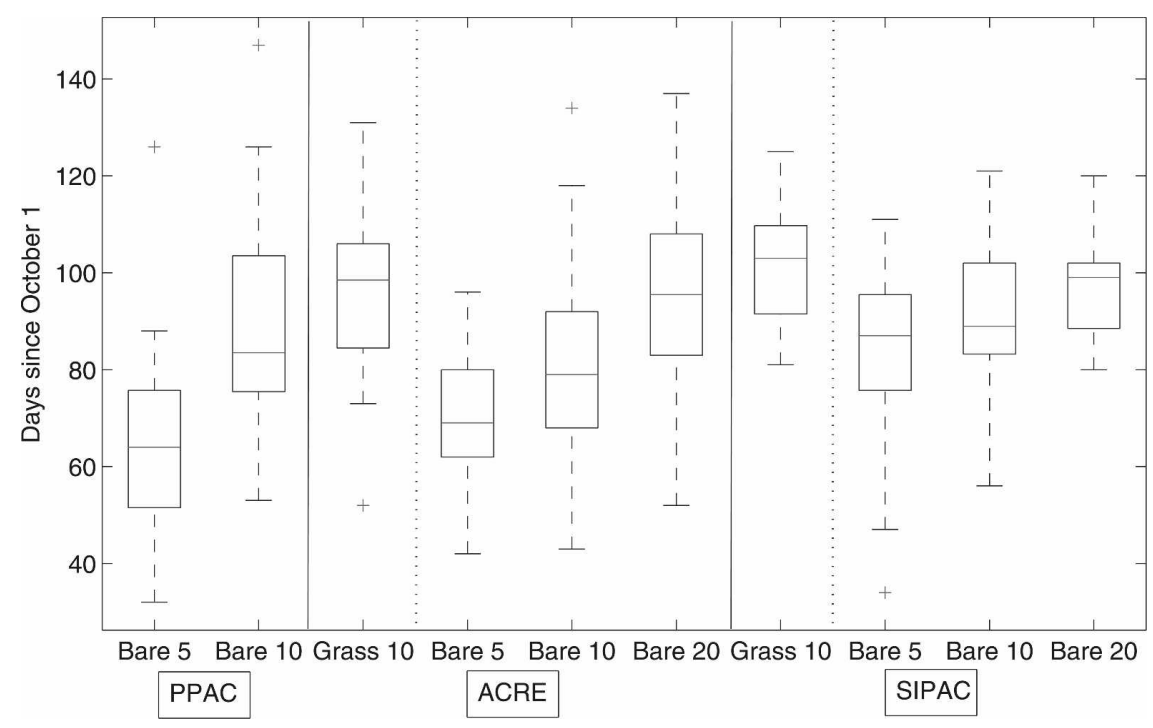

FIG. 2. Box plot illustrating the first day of soil frost at depths of 5,10 , and $20 \mathrm{~cm}$ below bare soil, and $10 \mathrm{~cm}$ below grass for all three sites. The plus sign indicates the outliers, and the horizontal line represents the median. The lower tail of the box represents the minimum value, whereas the upper tail represents the maximum value of a series. The lower edge of the box represents the $25 \%$ quartile, and the upper edge of the box represents the $75 \%$ quartile. 


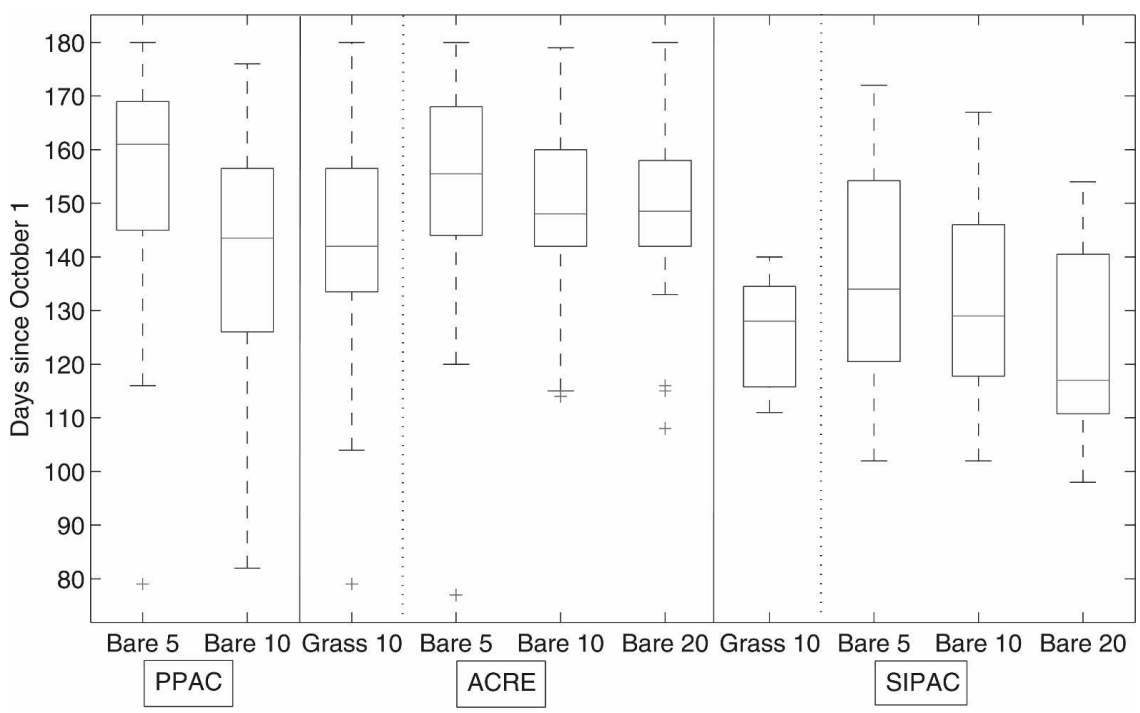

FIG. 3. Same as Fig. 2, but for last day of thaw.

$52 \%$ fewer freeze-thaw cycles and $49 \%$ fewer days with soil frost at a depth of $10 \mathrm{~cm}$ as compared to the observations under bare soil. Similarly, at SIPAC, the reductions in average annual freeze-thaw cycles and soil frost days as a result of the presence of grass on the soil surface are about $75 \%$ and $71 \%$, respectively.

\section{b. Analysis of annual average freezing and thawing dates}

The Kruskal-Wallis test is used to identify statistically significant differences in the median values of average annual first day of soil freezing and last day of
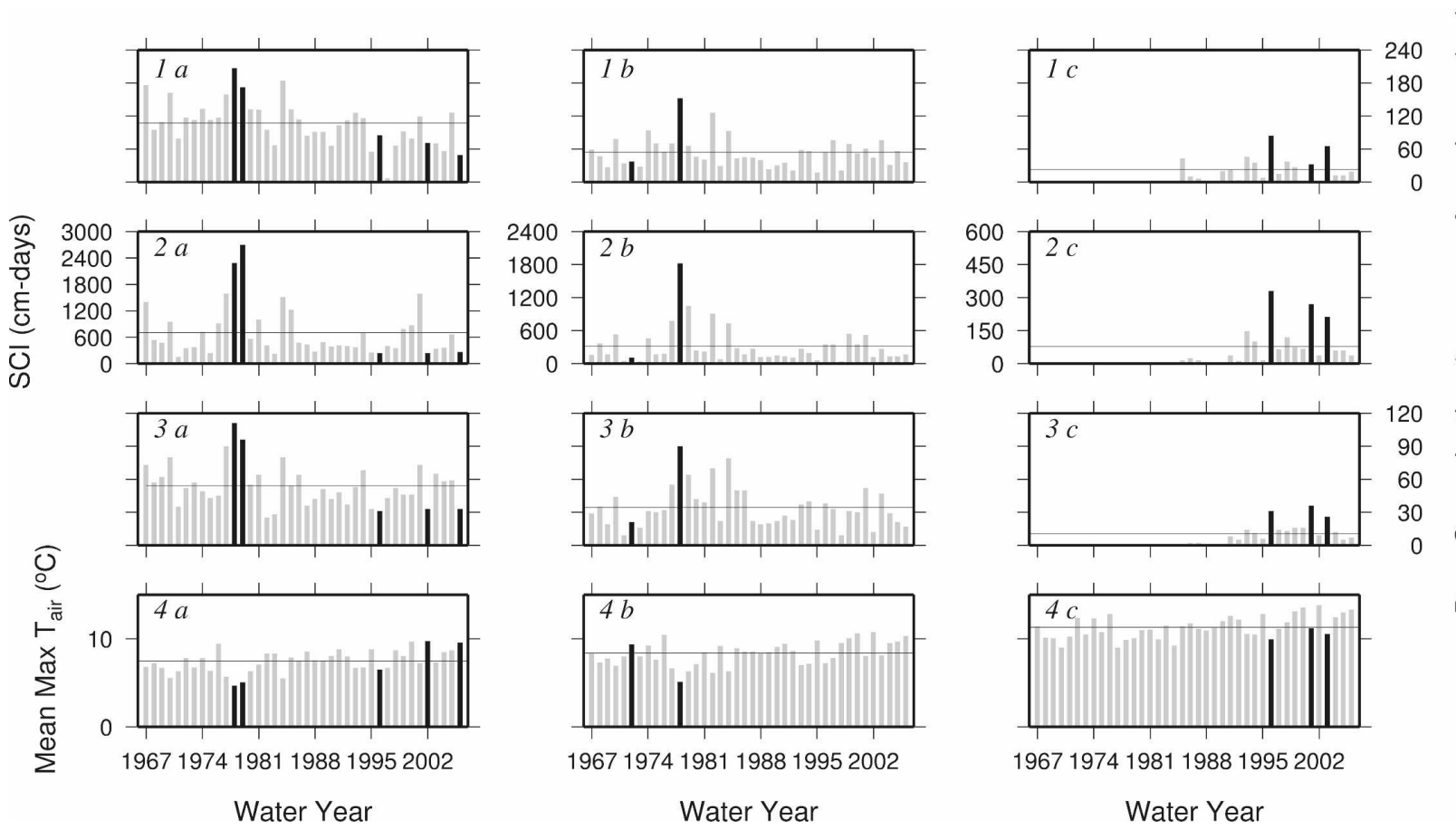

FIG. 4. Annual and cold season time series of selected variables estimated from meteorological observations with letters representing the following stations: (a) PPAC, (b) ACRE, and (c) SIPAC and numbers representing the following variables: (1) annual snowfall (cm), (2) annual SCI (cm days), (3) number of days when snow depth is greater than zero, and (4) seasonal mean maximum $T_{\text {air }}\left({ }^{\circ} \mathrm{C}\right)$. The continuous line indicates the annual mean value. The black bars indicate annual values discussed in the text. 

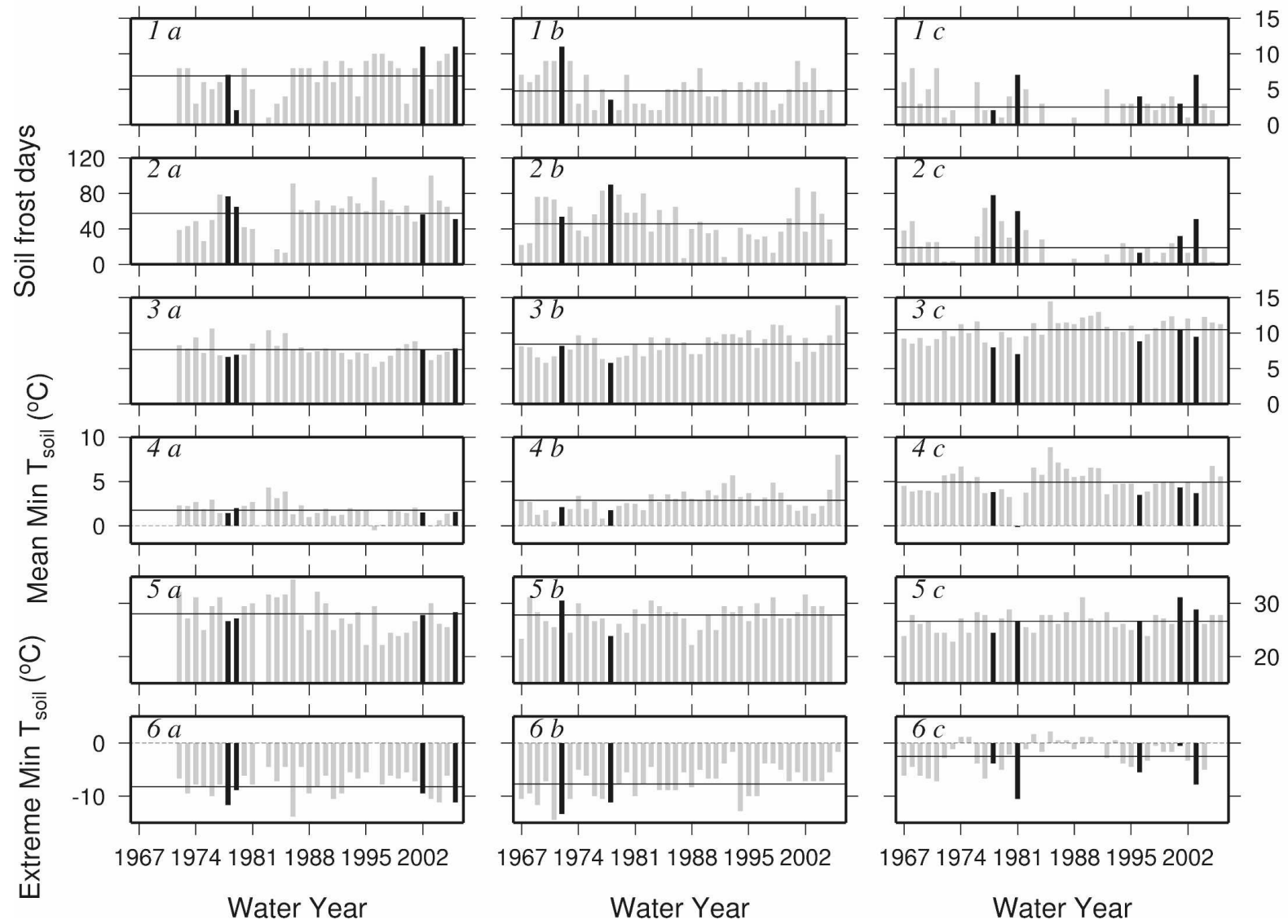

FIG. 5. Annual and cold season time series of selected variables estimated from soil temperature measurements at a depth of $5 \mathrm{~cm}$ below bare soil with letters representing the following stations: (a) PPAC, (b) ACRE, and (c) SIPAC and numbers representing the following variables: (1) annual freeze-thaw cycles (numbers), (2) annual soil frost days (numbers), (3) seasonal mean maximum $T_{\text {soil }}$ $\left({ }^{\circ} \mathrm{C}\right)$, (4) seasonal mean minimum $T_{\text {soil }}\left({ }^{\circ} \mathrm{C}\right),(5)$ seasonal extreme maximum $T_{\text {soil }}\left({ }^{\circ} \mathrm{C}\right)$, and (6) seasonal extreme minimum $T_{\text {soil }}\left({ }^{\circ} \mathrm{C}\right)$. The continuous line indicates the annual mean value. The black bars indicate annual values discussed in the text.

thaw. As expected, soils near the ground surface freeze earlier and thaw later than the soils at deeper depths (Figs. 2 and 3). Test results indicate significant differences in the median dates of soil freezing and thawing at both 5- and 10-cm depths below bare soil at the three sites. At a depth of $5 \mathrm{~cm}$, PPAC freezes in early December (the 64th day of the water year), which is 5 days earlier than ACRE and 23 days earlier than SIPAC (Fig. 2). Similarly, the last thaw in spring at a depth of $5 \mathrm{~cm}$ occurs around 11 March (161st day) at PPAC, 5 and 27 days later than the median thawing dates at ACRE and SIPAC, respectively (Fig. 3). This is directly related to the differences in the number of days with below freezing $T_{\text {air }}$ among the sites. However, at a depth of $10 \mathrm{~cm}$ below bare soil, ACRE's soil freezes earlier and thaws later than those at PPAC and SIPAC. ACRE freezes around 18 December, which is 5 days earlier than PPAC and 10 days earlier than SIPAC, respectively (Fig. 2). At this depth, the earlier freezing at ACRE in comparison to PPAC may be a result of lower average annual snowfall and SCI at ACRE, which would leave its soils more exposed to cold $T_{\text {air }}$ than the deeper snowpack at PPAC. Because the sites have very similar numbers of days with freezing air temperatures and differences in soil type would favor the earlier freezing of deeper soils at PPAC, the effect of snow cover is clearly an important factor in controlling soil frost dynamics.

At the deeper depth of $20 \mathrm{~cm}$ below bare soil, the average annual median dates of first freeze are not significantly different between ACRE and SIPAC, whereas there are no measurements at PPAC. ACRE's soil freezes about three days earlier than SIPAC's soil but both freezes occur in early January when $T_{\text {air }}$ is consistently below freezing. However, ACRE thaws about 30 days later than SIPAC because the more 

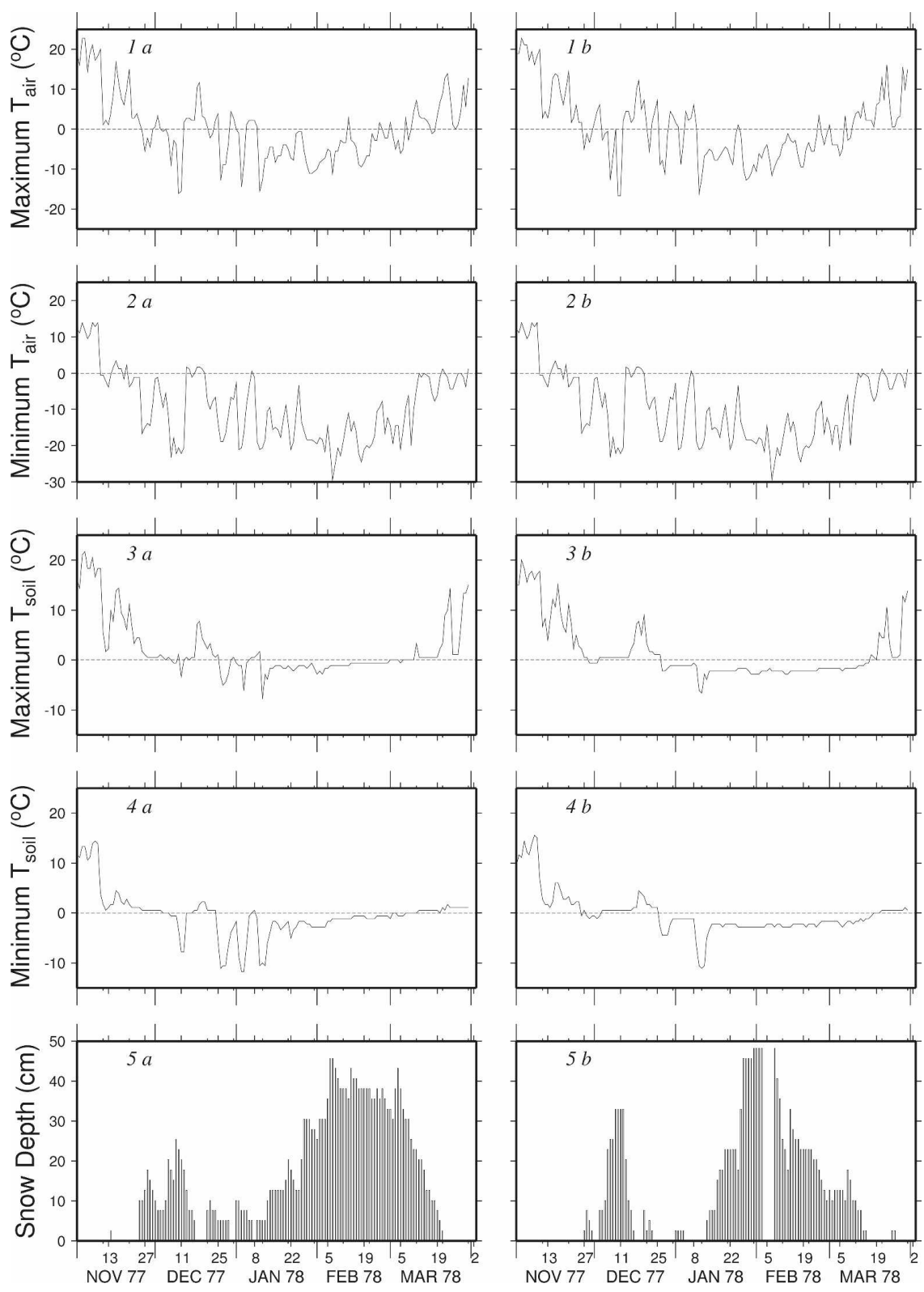

FIG. 6. Daily time series for the winter of 1978 at a depth of $5 \mathrm{~cm}$ below bare soil for sites: (a) PPAC and (b) ACRE. The following variables are presented: (1) maximum $T_{\text {air }}\left({ }^{\circ} \mathrm{C}\right),(2)$ minimum $T_{\text {air }}\left({ }^{\circ} \mathrm{C}\right)$, (3) maximum $T_{\text {soil }}\left({ }^{\circ} \mathrm{C}\right)$, (4) minimum $T_{\text {soil }}\left({ }^{\circ} \mathrm{C}\right)$, and (5) snow depth $(\mathrm{cm})$.

southern sites experience fewer days with $T_{\text {air }}$ below freezing.

\section{c. Annual average values for selected variables}

Using SCI as an indicator of significant snowfall, the winters of 1978 and 1979 at PPAC; 1978 at ACRE; and 1996, 2001, and 2003 at SIPAC stand out from the historical record (Fig. 4). All of these winters experienced below-average seasonal mean maximum $T_{\text {air }}$ with above-average number of days with snow cover. Snow observations from SIPAC prior to 1985 are not consis- tent enough to use in this analysis; therefore, the winter of 1978 cannot be compared across sites. The magnitude of maximum SCI for PPAC is about 1.5 times that of ACRE, whereas it is 8.2 times that of SIPAC. Therefore, the insulating effect of maximum SCI at SIPAC is equivalent to an average year at ACRE and a year substantially below average at PPAC.

At a depth of $5 \mathrm{~cm}$, freeze-thaw cycles at PPAC for 1978 and 1979 and at ACRE for 1978 are at or below annual average values, whereas the number of days with soil frost is above average, indicating substantial 

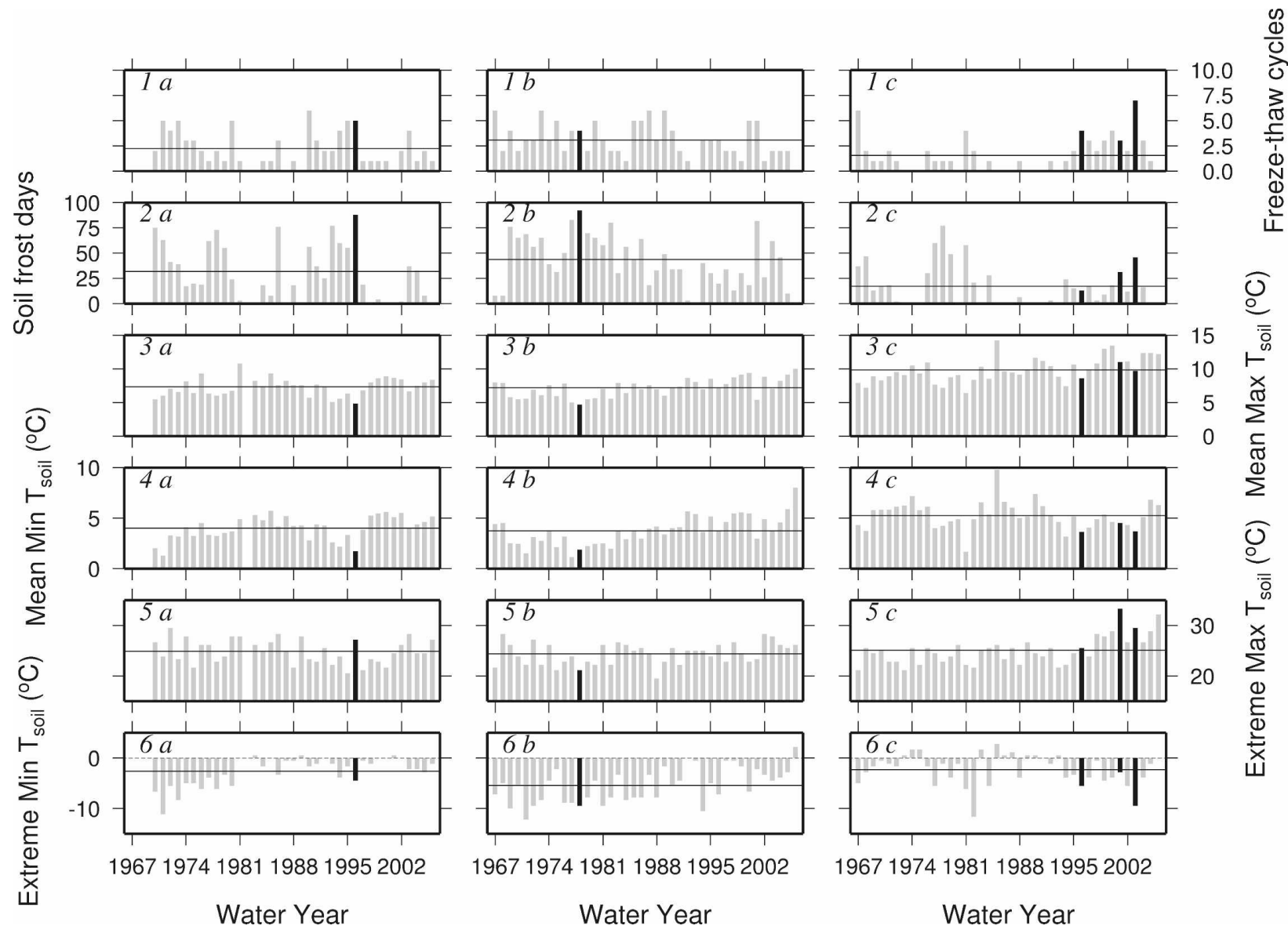

FIG. 7. Same as Fig. 5, but measurements at a depth of $10 \mathrm{~cm}$.

seasonal frost (Figs. 5, 1a-6b). Soil temperatures for those winters are generally below average, despite the substantial snow cover. Because the snowpack is near its maximum and $T_{\text {air }}$ is at its minimum, it is impossible to separate their effects from the annual averages. Daily values for the winter of 1978 at both sites (Fig. 6) illustrate that the snowpack is thin in December and mid-January, leading to very cold $5 \mathrm{~cm} T_{\text {soil }}$. Furthermore, snow depths greater than $10 \mathrm{~cm}$ significantly reduce the impact of cold $T_{\text {air }}$ in February and midMarch. For the duration of the deep snow cover, $T_{\text {soil }}$ is relatively constant despite highly fluctuating $T_{\text {air }}$ at both PPAC and ACRE.

At a depth of $5 \mathrm{~cm}$, years with higher SCI values at SIPAC (1996, 2001, and 2003) experienced a higher than average number of freeze-thaw cycles and days with soil frost, except for 1996 when the number of soil frost days was below average (Figs. 5, 1c-6c). Despite the deeper snowpack in years with higher SCI at SIPAC, $T_{\text {soil }}$ variables are generally below average, except for the seasonal extreme maximum $T_{\text {soil }}$. These years also indicate similar relationships for SCI, freeze- thaw cycles, soil frost days, and $T_{\text {soil }}$ at a depth of $10 \mathrm{~cm}$, except for the above-average seasonal mean maximum $T_{\text {soil }}$ in 2001 (Figs. 7, 1c-6c). At a depth of $10 \mathrm{~cm}$, the winter of 2003 experienced the highest number of freeze-thaw cycles at SIPAC. The variability in $T_{\text {soil }}$ for 2003 can be explained by looking at the daily time series for the winter at a depth of $10 \mathrm{~cm}$ (Fig. 8). Freezing does not occur until mid-January when snow cover is less than $5 \mathrm{~cm}$, which allows minimum $T_{\text {soil }}$ to reach nearly $-10^{\circ} \mathrm{C}$ prior to thawing. A second freeze occurs in February, this time in conjunction with snow accumulations greater than $10 \mathrm{~cm}$, which significantly damps temperature variation. Although SCI is close to the observed maximum at SIPAC, deeper snow accumulations last for less than half a month, minimizing its effectiveness as insulation for the soil surface.

At a depth of $5 \mathrm{~cm}$, PPAC experienced an aboveaverage number of freeze-thaw cycles in both 2002 and 2006 and at a depth of $10 \mathrm{~cm}$ in 1996 (Figs. 5 and 7; 1a and $2 \mathrm{a}$ ). The number of soil frost days at PPAC is also higher in these years, except in 2006 at 5 -cm soil depth. During these years, snowfall and SCI are below average 


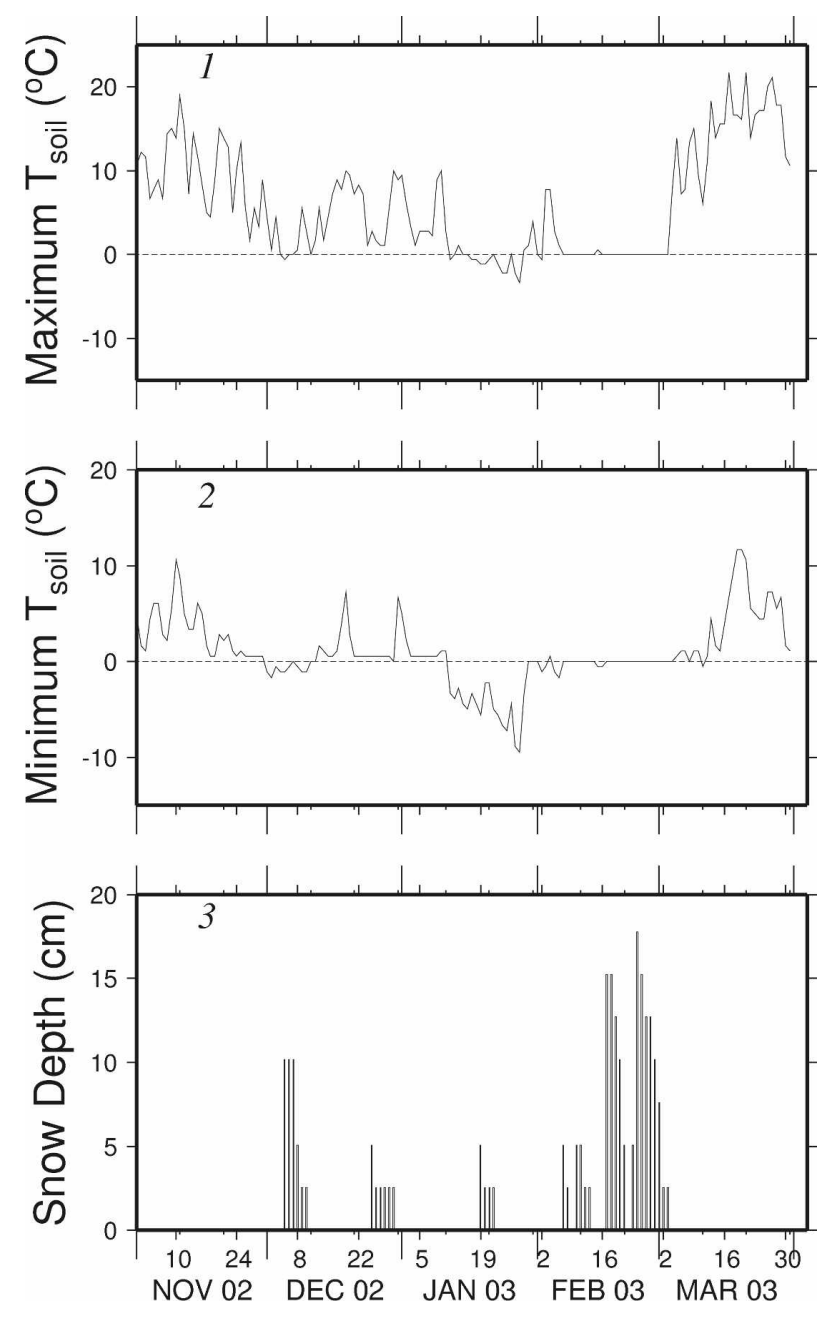

FIG. 8. Daily time series for the winter of 2003 at SIPAC for a depth of $10 \mathrm{~cm}$ below bare soil for the following variables: (1) minimum $T_{\text {soil }}\left({ }^{\circ} \mathrm{C}\right)$, (2) maximum $T_{\text {soil }}\left({ }^{\circ} \mathrm{C}\right)$, and (c) snow depth $(\mathrm{cm})$.

for PPAC, with colder seasonal temperatures including mean maximum $T_{\text {soil }}$, mean minimum $T_{\text {soil }}$, and extreme minimum $T_{\text {soil }}$ (Figs. 4, 1a and 2a; 5, 4a-6a). Similar relationships between freeze-thaw cycles, soil frost days, snowfall, SCI, and $T_{\text {soil }}$ are observed at ACRE in 1972 at a depth of $5 \mathrm{~cm}$ as well as at a depth of $10 \mathrm{~cm}$ below bare soil in 1978 (Figs. 4, 1b and 2b; 5 and 7, 1b-6b). SIPAC also observes more days of soil frost in 1978 and 1981, corresponding to below-average seasonal mean maximum and seasonal mean minimum $T_{\text {soil }}$ (Figs. 5, 1c-4c). This indicates that as $T_{\text {soil }}$ becomes colder, the number of soil frost days increases.

\section{d. Autocorrelation results}

Significant autocorrelations are determined using a $5 \%$ significance level for the variables described in sec-
TABLE 2a. Summary of significant autocorrelations for meteorological variables. Numbers indicate the lag (in years) at which autocorrelation is significant at a level of $5 \%$. The letter $\mathrm{N}$ indicates no significant autocorrelation.

\begin{tabular}{lccc}
\hline & PPAC & ACRE & SIPAC \\
\hline Days minimum $T_{\text {air }} \leq 0^{\circ} \mathrm{C}$ & $\mathrm{N}$ & $\mathrm{N}$ & $\mathrm{N}$ \\
Mean maximum $T_{\text {air }}$ (seasonal) & $\mathrm{N}$ & $\mathrm{N}$ & $\mathrm{N}$ \\
Mean minimum $T_{\text {air }}$ (seasonal) & $\mathrm{N}$ & $\mathrm{N}$ & $\mathrm{N}$ \\
Snow (annual)* & 1 & $\mathrm{~N}$ & $\mathrm{~N}$ \\
SCI (annual)* & 1 & 1 & $\mathrm{~N}$ \\
Precipitation (seasonal and annual) & $\mathrm{N}$ & $\mathrm{N}$ & $\mathrm{N}$ \\
\hline
\end{tabular}

* Estimated from 1985 to 2006 at SIPAC.

tion 2c. Observations since 1967 indicate that most of the meteorological data and soil temperature data series do not have significant autocorrelations (Table 2a). Soil temperature derived variables are statistically autocorrelated in just under half of the cases tested (Table $2 b$ ). Derived variables under grass and at a depth of 20 $\mathrm{cm}$ have the fewest occurrences of significant autocorrelation.

\section{e. Time series trend analysis}

\section{1) Meteorological variables}

Trend analysis, based upon observations from 1967 to 2006, indicates that annual snowfall is decreasing at PPAC (Table 3a), but no other snow variable time series are experiencing statistically significant trends. There are no significant trends in the number of days with $T_{\text {air }}$ less than $0^{\circ} \mathrm{C}$, but seasonal mean maximum $T_{\text {air }}$ is increasing at all three sites. Seasonal mean minimum $T_{\text {air }}$ is also increasing, though it is statistically significant only at SIPAC. No significant trend is observed in seasonal or annual precipitation.

\section{2) Soil temperature VARiables}

At PPAC, trend analysis indicates that freeze-thaw cycles at a depth of $5 \mathrm{~cm}$ below bare soil have been increasing since 1972 (Table 3b). This may be a result of a reduction in annual snowfall, which decreases soil insulation and exposes it to the greater variability of $T_{\text {air }}$. Observations also indicate that seasonal mean minimum $T_{\text {soil }}$ and seasonal extreme maximum $T_{\text {soil }}$ are decreasing at PPAC (Table 3b), suggesting that $T_{\text {soil }}$ has become colder. However, seasonal temperatures at ACRE including mean maximum $T_{\text {soil }}$, mean minimum $T_{\text {soil }}$, and extreme minimum $T_{\text {soil }}$ at a depth of $5 \mathrm{~cm}$ are increasing since 1967, indicating warming in $T_{\text {soil }}$. A similar warming trend in $T_{\text {soil }}$ is observed at SIPAC at a depth of $5 \mathrm{~cm}$, but it is confined only to seasonal mean maximum $T_{\text {soil }}$. 
TABLE 2b. Summary of significant autocorrelations for variables estimated from observed soil temperatures $\left(T_{\text {soil }}\right)$. Numbers indicate the lag (in years) at which autocorrelation is significant at a level of $5 \%$. The letter $\mathrm{N}$ indicates no significant autocorrelation.

\begin{tabular}{|c|c|c|c|c|c|c|c|c|c|c|}
\hline \multirow[b]{3}{*}{ Soil depth $(\mathrm{cm})$ : } & \multirow{2}{*}{\multicolumn{2}{|c|}{$\frac{\text { PPAC }}{\text { Bare soil }}$}} & \multicolumn{4}{|c|}{ ACRE } & \multicolumn{4}{|c|}{ SIPAC } \\
\hline & & & \multirow{2}{*}{$\begin{array}{c}\text { Grass }^{\mathrm{a}} \\
10\end{array}$} & \multicolumn{3}{|c|}{ Bare soil } & \multirow{2}{*}{$\begin{array}{c}\text { Grass }^{\mathrm{a}} \\
10\end{array}$} & \multicolumn{3}{|c|}{ Bare soil } \\
\hline & $5^{\mathrm{b}}$ & $10^{\mathrm{c}}$ & & 5 & 10 & 20 & & 5 & 10 & 20 \\
\hline Soil freeze-thaw cycles & $\mathrm{N}$ & 1 & $\mathrm{~N}$ & $\mathrm{~N}$ & $\mathrm{~N}$ & $\mathrm{~N}$ & $\mathrm{~N}$ & $\mathrm{~N}$ & 1 & $\mathrm{~N}$ \\
\hline Soil frost days & 1 & $\mathrm{~N}$ & $\mathrm{~N}$ & 1 & 1 & $\mathrm{~N}$ & $\mathrm{~N}$ & 1 & 1 & $\mathrm{~N}$ \\
\hline Mean maximum $T_{\text {soil }}$ (seasonal) & $\mathrm{N}$ & $\mathrm{N}$ & $\mathrm{N}$ & 1 & 2 & 2 & $\mathrm{~N}$ & 2 & 1 & $\mathrm{~N}$ \\
\hline Mean minimum $T_{\text {soil }}$ (seasonal) & 2 & 2 & $\mathrm{~N}$ & 1 & 2 & $\mathrm{~N}$ & 2 & 1 & 1 & $\mathrm{~N}$ \\
\hline Extreme maximum $T_{\text {soil }}$ (seasonal) & $\mathrm{N}$ & $\mathrm{N}$ & $\mathrm{N}$ & $\mathrm{N}$ & $\mathrm{N}$ & $\mathrm{N}$ & $\mathrm{N}$ & $\mathrm{N}$ & $\mathrm{N}$ & $\mathrm{N}$ \\
\hline Extreme minimum $T_{\text {soil }}$ (seasonal) & $\mathrm{N}$ & 3 & $\mathrm{~N}$ & $\mathrm{~N}$ & $\mathrm{~N}$ & $\mathrm{~N}$ & $\mathrm{~N}$ & 1 & $\mathrm{~N}$ & 1 \\
\hline
\end{tabular}

${ }^{\text {a }}$ Grass estimated from 1967 to 2001.

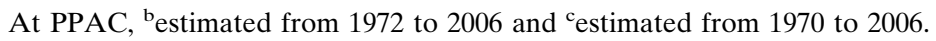

For deeper layers under bare soil, all statistically significant trends reflect a warming of the soil, except for the $20-\mathrm{cm}$ seasonal extreme maximum $T_{\text {soil }}$ at SIPAC (Table $3 b$ ). The only statistically significant changes in soil frost variables occur at ACRE, where the number of soil freeze-thaw cycles is decreasing at $10 \mathrm{~cm}$, and the number of soil frost days is decreasing at 10 and $20 \mathrm{~cm}$ below bare soil. This follows directly from the observed increases in soil temperature variables. Measurements at $10 \mathrm{~cm}$ under grass at SIPAC show a statistically significant increase in seasonal mean maximum $T_{\text {soil }}$ similar to that observed at the bare soil site. Trends at the ACRE grass site are opposite of the other deep soil sites, with significant decreases in seasonal mean minimum and extreme minimum $T_{\text {soil }}$, and a corresponding increase in the number of freeze-thaw cycles.

\section{Conclusions}

In this study, hydrologic time series analysis is performed to identify statistically significant trends in soil frost variables and soil temperatures at several depths for three research stations located in northern (PPAC), central (ACRE), and southern (SIPAC) Indiana. Seasonal and annual variability, and trends in soil frost variables are compared with other meteorological observations from 1966 to 2006. An analysis of average annual statistics for meteorological variables indicates that snow cover at the central site is half that of the northern site and twice that of the southern site. Days with air temperatures below freezing and annual precipitation are similar between the northern and the central sites, whereas the southern site experiences nearly a month fewer days of freezing air temperatures and nearly $25 \mathrm{~cm}$ more annual precipitation. Therefore, snow cover is the dominant factor in the differences in soil frost between the central and northern sites, whereas the southern site is in a substantially different climate.
An analysis of the annual average variables for the three sites demonstrates that ground snow cover, especially when deeper than $10 \mathrm{~cm}$, acts as an insulating layer between the soil surface and colder winter air temperatures, leading to fewer fluctuations of soil temperature during years with significant surface snow accumulation. This results in fewer freeze-thaw cycles, but it is not a predictor of the duration of soil frost (the number of soil frost days), which also depends on the duration and timing of snow cover on the ground surface. Thinner ground snow cover does correspond to an increase in the number of soil frost days and fewer soil freeze-thaw cycles as well as colder soil temperatures. Freeze-thaw cycles are additionally governed by climatic factors such as air temperature, precipitation, and soil moisture.

A statistical trend analysis of the meteorological variables indicates an increase in seasonal mean maximum $T_{\text {air }}$ at all sites as well as an increase in the seasonal mean minimum $T_{\text {air }}$ at SIPAC for the period of analysis. There are no significant changes in other air temperature variables or in precipitation. Annual snowfall is decreasing significantly at PPAC, but there are no other significant trends in snow cover variables.

TABLE 3a. Summary of the significant trends obtained from Mann-Kendall's statistical test for meteorological variables. The letter $\mathrm{N}$ indicates the absence of statistically significant trend with a significance level of $5 \%$. The up and down arrows indicate statistically significant increasing and decreasing trends, respectively.

\begin{tabular}{lccc}
\hline \hline & PPAC & ACRE & SIPAC \\
\hline Days minimum $T_{\text {air }} \leq 0^{\circ} \mathrm{C}$ & $\mathrm{N}$ & $\mathrm{N}$ & $\mathrm{N}$ \\
Mean maximum $T_{\text {air }}$ (seasonal) & $\uparrow$ & $\uparrow$ & $\uparrow$ \\
Mean minimum $T_{\text {air }}$ (seasonal) & $\mathrm{N}$ & $\mathrm{N}$ & $\uparrow$ \\
Snow (annual)* & $\downarrow$ & $\mathrm{N}$ & $\mathrm{N}$ \\
Snow Cover Index (annual)* & $\mathrm{N}$ & $\mathrm{N}$ & $\mathrm{N}$ \\
Precipitation (seasonal and annual) & $\mathrm{N}$ & $\mathrm{N}$ & $\mathrm{N}$ \\
\hline
\end{tabular}

* SIPAC trends are estimated from 1985 to 2006. 
TABLE 3b. Summary of the significant trends obtained from Mann-Kendall's statistical test for variables estimated from soil temperatures as described in section $2 \mathrm{c}$. The letter $\mathrm{N}$ indicates the absence of statistically significant trend with a significance level of $5 \%$. The up and down arrows indicate statistically significant increasing and decreasing trends, respectively.

\begin{tabular}{|c|c|c|c|c|c|c|c|c|c|c|}
\hline \multirow[b]{3}{*}{ Soil depth $(\mathrm{cm})$ : } & \multirow{2}{*}{\multicolumn{2}{|c|}{$\begin{array}{c}\text { PPAC } \\
\text { Bare soil }\end{array}$}} & \multicolumn{4}{|c|}{ ACRE } & \multicolumn{4}{|c|}{ SIPAC } \\
\hline & & & \multirow{2}{*}{$\begin{array}{c}\text { Grass }^{\mathrm{a}} \\
10\end{array}$} & \multicolumn{3}{|c|}{ Bare soil } & \multirow{2}{*}{$\begin{array}{c}\text { Grass }^{\mathrm{a}} \\
10\end{array}$} & \multicolumn{3}{|c|}{ Bare soil } \\
\hline & $5^{b}$ & $10^{\mathrm{c}}$ & & 5 & 10 & 20 & & 5 & 10 & 20 \\
\hline Soil freeze-thaw cycles & $\uparrow$ & $\mathrm{N}$ & $\uparrow$ & $\mathrm{N}$ & $\downarrow$ & $\mathrm{N}$ & $\mathrm{N}$ & $\mathrm{N}$ & $\mathrm{N}$ & $\mathrm{N}$ \\
\hline Soil frost days & $\mathrm{N}$ & $\mathrm{N}$ & $\mathrm{N}$ & $\mathrm{N}$ & $\downarrow$ & $\downarrow$ & $\mathrm{N}$ & $\mathrm{N}$ & $\mathrm{N}$ & $\mathrm{N}$ \\
\hline Mean maximum $T_{\text {soil }}$ (seasonal) & $\mathrm{N}$ & $\mathrm{N}$ & $\mathrm{N}$ & $\uparrow$ & $\uparrow$ & $\uparrow$ & $\uparrow$ & $\uparrow$ & $\uparrow$ & $\mathrm{N}$ \\
\hline Mean minimum $T_{\text {soil }}$ (seasonal) & $\downarrow$ & $\mathrm{N}$ & $\downarrow$ & $\uparrow$ & $\uparrow$ & $\uparrow$ & $\mathrm{N}$ & $\mathrm{N}$ & $\mathrm{N}$ & $\mathrm{N}$ \\
\hline Extreme maximum $T_{\text {soil }}$ (seasonal) & $\downarrow$ & $\mathrm{N}$ & $\mathrm{N}$ & $\mathrm{N}$ & $\mathrm{N}$ & $\mathrm{N}$ & $\mathrm{N}$ & $\mathrm{N}$ & $\uparrow$ & $\downarrow$ \\
\hline Extreme minimum $T_{\text {soil }}$ (seasonal) & $\mathrm{N}$ & $\uparrow$ & $\downarrow$ & $\uparrow$ & $\uparrow$ & $\uparrow$ & $\mathrm{N}$ & $\mathrm{N}$ & $\mathrm{N}$ & $\uparrow$ \\
\hline
\end{tabular}

a Grass estimated from 1967 to 2001.

At PPAC, ${ }^{b}$ trends are estimated from 1972 to 2006 and ${ }^{c}$ trends are estimated from 1970 to 2006.

An analysis of trends in soil temperature variables indicates that in northern Indiana, the number of freeze-thaw cycles at a depth of $5 \mathrm{~cm}$ is increasing and soil temperatures on average are getting colder. This is contrary to the warming trend in air temperature but likely related to the observed decrease in snowfall, which reduces its accumulation. This increases the exposure of soil surface to warmer, though still freezing, air temperatures during the cold season. Significant soil temperature trends under bare soil at the central and the southern Indiana sites indicate warming, except seasonal extreme maximum temperatures at a depth of $20 \mathrm{~cm}$ at SIPAC. The only significant trends in soil frost variables occur at the central site, where the number of freeze-thaw cycles at a depth of $10 \mathrm{~cm}$ below bare soil and the number of days with soil frost at both 10- and 20 -cm depths are decreasing. This reduction in soil frost agrees with the warming trends observed in the soil and air temperatures. The seasonal mean maximum soil temperature under grass cover is increasing at the southern site, as it is under bare soil. Observations from the grass site at ACRE, however, indicate the cold season soil minimum temperatures are decreasing significantly, whereas the number of freeze-thaw cycles is increasing.

An analysis of soil and climatic variables from 1966 through 2006 clearly indicates that air temperatures are increasing in Indiana, but significant trends in snowfall are limited to the northern part of the state. Southern and central Indiana are experiencing a warming in soil temperatures related to the increase in air temperature, whereas soils at the northern site are, in fact, getting colder, most likely because the decrease in annual snowfall is reducing the insulation of the soil surface.

Acknowledgments. The authors thank NASA for providing funding for this research through the Grant
NNG04GP13P. The authors are also thankful to Dr. Eileen J. Kladivko (Agronomy Department, Purdue University) for her helpful discussions and comments. The authors appreciate the suggestions of the reviewers, which helped to improve the overall quality of this paper. This manuscript is Purdue Climate Change Research Center (PCCRC) Paper 0716.

\section{REFERENCES}

Baker, D. G., and D. L. Ruschy, 1995: Calculated and measured air and soil freeze-thaw frequencies. J. Appl. Meteor., 34, 2197-2205.

Baldwin, C. K., and U. Lall, 1999: Seasonality of streamflow: The upper Mississippi River. Water Resour. Res., 35, 1143-1154.

Bayard, D., M. Stahli, A. Parriaux, and H. Fluhler, 2005: The influence of seasonally frozen soil on the snowmelt runoff at two Alpine sites in southern Switzerland. J. Hydrol., 309, 66-84.

Benoit, G. R., and J. Bornstein, 1970: Freezing and thawing effects on drainage. Soil Sci. Soc. Amer. J., 34, 551-557.

Benson, C. H., T. H. Abichou, M. A. Olson, and P. J. Bosscher, 1995: Winter effects on hydraulic conductivity of compacted clay. J. Geotech. Eng., 121, 69-79.

Birsan, M.-V., P. Molnar, P. Burlando, and M. Pfaundler, 2005: Streamflow trends in Switzerland. J. Hydrol., 314, 312-329.

Bryan, R. B., 1971: The influence of frost action on soil-aggregate stability. Trans. Inst. Br. Geogr., 54, 71-88.

Cherkauer, K. A., and D. P. Lettenmaier, 1999: Hydrologic effects of frozen soils in the upper Mississippi River basin. J. Geophys. Res., 104, 19 599-19 610.

— and -2003 : Simulation of spatial variability in snow and frozen soil. J. Geophys. Res., 108, 8858, doi:10.1029/ 2003JD003575.

Dale, R. F., B. C. Reinke, and J. E. Wright, 1981: Freeze-thaw cycles in Indiana soils. Proc. Indiana Acad. Sci., 90, 408-415.

Department of Commerce, 1966-1982: Indiana. Climatological Data, Vols. 71-87, Environmental Data and Information Service, National Climatic Data Center.

Departments of the Army and the Air Force, 1987: Arctic and subarctic construction: General provisions, Tech. Manual TM 5-852-1/AFR 88-19, Vol. 1, 55 pp. 
Dunne, T., and R. D. Black, 1971: Runoff processes during snowmelt. Water Resour. Res., 7, 1160-1172.

Feng, S., Q. Hu, and W. Qian, 2004: Quality control of daily meteorological data in China, 1951-2000: A new dataset. Int. J. Climatol., 24, 853-870.

Ferrick, M. G., and L. W. Gatto, 2004: Quantifying the effect of a freeze-thaw cycle on soil erosion: Laboratory experiments. U.S. Army Corps of Engineers Engineer Research and Development Center Letter Rep. ERDC/CRREL LR-04-16, 47 pp.

Froese, J. C., M. C. Cruse, and M. Ghaffarzadeh, 1999: Erosion mechanics of soils with an impermeable subsurface layer. Soil Sci. Soc. Amer. J., 3, 1836-1841.

Gatto, L. W., and M. G. Ferrick, 2003: Overland erosion due to freeze-thaw cycling: Laboratory experiments. U.S. Army Corps of Engineers Engineer Research and Development Center Tech. Note ERDC/CRREL TN-03-3, 22 pp.

Groisman, P. Ya., T. R. Karl, R. W. Knight, and G. L. Stenchikov, 1994: Changes of snow cover, temperature, and radiative heat balance over the Northern Hemisphere. J. Climate, 7, 16331656.

Hamed, K. H., and A. R. Rao, 1998: A modified Mann-Kendall trend test for autocorrelated data. J. Hydrol., 204, 182-196.

Hardy, J. P., and Coauthors, 2001: Snow depth manipulation and its influence on soil frost and water dynamics in a northern hardwood forest. Biogeochemistry, 56, 151-174.

Hershfield, D. M., 1974: The frequency of freeze-thaw cycles. $J$. Appl. Meteor., 13, 348-354.

Hillel, D., 1998: Soil structure and aggregation. Environmental Soil Physics, Academic Press, 101-125.

Hirsch, R. M., D. R. Helsel, T. A. Cohn, and E. J. Gilroy, 1992: Statistical analysis of hydrologic data. Handbook of Hydrology, D. R. Maidment, Ed., McGraw-Hill, 17.1-17.55.

$\mathrm{Hu}$, Q., and S. Feng, 2003: A daily temperature dataset and soil temperature climatology of the contiguous United States. $J$. Appl. Meteor., 42, 1139-1156.

- — - and G. Schaefer, 2002: Quality control for USDA NRCS SM-ST network soil temperatures: A method and a dataset. J. Appl. Meteor., 41, 607-619.

Kane, D. L., and E. F. Chacho, 1990. Frozen ground effects on infiltration and runoff. Cold Regions Hydrology and Hydraulics: A State of the Practice Report, Technical Council on Cold Regions, Eng. Mongr., American Society of Civil Engineers, 259-300.

Kling, G. W., and Coauthors, 2003: Confronting climate change in Great Lakes region: Impacts on our communities and ecosystems. The Union of Concerned Scientists and the Ecological Society of America, $92 \mathrm{pp}$.

Knox, J. C., 2001: Agricultural influence on landscape sensitivity in the Upper Mississippi River Valley. Catena, 42, 193-224.

Kunkel, K. E., K. Andsager, and D. A. Easterling, 1999: Longterm trends in extreme precipitation events over the conterminous United States and Canada. J. Climate, 12, 2515-2527.

Lemke, P., and Coauthors, 2007: Observations: Changes in snow, ice and frozen ground. Climate Change 2007: The Physical
Science Basis, S. Solomon, et al., Eds., Cambridge University Press, 337-384.

Lettenmaier, D. P., E. F. Wood, and J. R. Wallis, 1994: HydroClimatological trends in the continental United States, 1948-88. J. Climate, 7, 586-607.

Lins, H. F., and J. R. Slack, 1999: Streamflow trends in the United States. Geophys. Res. Lett., 26, 227-230.

Nyberg, L., M. Stahli, P. Mellander, and K. H. Bishop, 2001: Soil frost effects on soil water and runoff dynamics along a boreal forest transect: 1. Field investigations. Hydrol. Process., 15, 909-926.

Rao, A. R., K. H. Hamed, and H.-L. Chen, 2003: Time domain analysis. Nonstationarities in Hydrologic and Environmental Time Series, V. P. Singh, Ed., Water Science and Technology Library, Vol. 45, Kluwer Academic, 27-54.

Reek, T., S. R. Doty, and T. W. Owen, 1992: A deterministic approach to the validation of historical daily temperature and precipitation data from the Cooperative Network. Bull. Amer. Meteor. Soc., 73, 753-762.

Schaal, L. A., J. E. Newman, and K. A. Scheeringa, 1981: Climatology of soil temperatures in Indiana. Department of Agronomy, Agricultural Experiment Station, Purdue University, Station Bulletin 307, 87 pp.

Schmidlin, T. W., B. E. Dethier, and K. L. Eggleston, 1987: Freeze-thaw days in the northeastern United States. J. Appl. Meteor., 26, 142-155.

Shanley, J. B., and A. Chalmers, 1999: The effect of frozen soil on snowmelt runoff at Sleepers River, Vermont. Hydrol. Processes, 13, 1843-1857.

Stadler, D., H. Wunderli, A. Auckenthaler, and H. Fluhler, 1996: Measurements of frost-induced snowmelt runoff in a forest soil. Hydrol. Processes, 10, 1293-1304.

Yue, S., and C. Y. Wang, 2002: Regional streamflow trend detection with consideration of both temporal and spatial correlation. Int. J. Climatol., 22, 933-946.

Zhang, T., 2005: Influence of the seasonal snow cover on the ground thermal regime: An overview. Rev. Geophys., 43, RG4002, doi:10.1029/2004RG000157.

_ and R. L. Armstrong, 2001: Soil freeze/thaw cycles over snow-free land detected by passive microwave remote sensing. Geophys. Res. Lett., 28, 763-766.

_ R. G. Barry, D. Gilichinsky, S. S. Bykhovets, V. A. Sorokovikov, and J. Ye, 2001: An amplified signal of climatic change in soil temperatures during the last century at Irkutsk, Russia. Climatic Change, 49, 41-76.

— A. Atringer, O. Frauenfeld, R. G. Barry, D. Gilichinsky, and M. Serreze, 2003: Climate change: Evidence from Russian historical soil temperature measurements. Geophysical Research Abstracts, Vol. 8, Abstract 05285.[Available online at http://www.cosis.net/abstracts/EGU06/05285/EGU06-J05285.pdf.]

Zhao, L., and D. M. Gray, 1999: Estimating snowmelt infiltration into frozen soils. Hydrol. Processes, 13, 1827-1842.

,$- \ldots$, and D. H. Male, 1997: Numerical analysis of simultaneous heat and mass transfer during infiltration into frozen ground. J. Hydrol., 200, 345-363. 
Copyright of Journal of Hydrometeorology is the property of American Meteorological Society and its content may not be copied or emailed to multiple sites or posted to a listserv without the copyright holder's express written permission. However, users may print, download, or email articles for individual use. 